\title{
Superimposed lateralized exanthem in a 30-year-old woman
}

\author{
Carmen María Alcántara-Reifs MD, Rafael Salido-Vallejo MD PhD
}

— Cite as: CMAJ 2017 September 11;189:E1146. doi: 10.1503/cmaj.170244

A

30-year-old woman presented with an asymptomatic papular rash of six days' duration, which began abruptly near her left axilla and spread along her lateral thoracic wall and abdomen. Subsequently, the involvement became bilateral, although a unilateral, left-sided predominance was maintained. The patient had experienced malaise and diarrhea a few days before the eruption. Physical examination showed numerous erythematoedematous, nonscaly, millimetre-sized papules with a tendency to coalesce on both sides of her body (Figure 1). There was no mucosal involvement. Her blood count and blood chemistry were within normal limits, but serology was positive for adenovirus. Based on the findings, we diagnosed superimposed lateralized exanthem.

Also known as unilateral laterothoracic exanthem or asymmetric periflexural exanthem, superimposed lateralized exanthem is a distinctive skin eruption that typically starts unilaterally in or around the axilla and spreads down the side of the trunk and medial surface of the corresponding arm. ${ }^{1}$ Because a less severe bilateral rash appears during the course of the disease in most cases, the term "superimposed lateralized exanthem" seems more suitable than "unilateral laterothoracic exanthem." The condition occurs mostly between infancy and the age of four years and it has only rarely been described in adults. ${ }^{1}$ It has been associated with viral infections including parvovirus B19, parainfluenza virus and adenovirus. ${ }^{1,3}$ The diagnosis is clinical; the differential diagnosis includes nonspecific viral rashes, contact dermatitis, toxicoderma and miliaria. ${ }^{4}$ The rash tends to resolve spontaneously within four to six weeks. Treatment is usually symptomatic.

\section{References}

1. Chuh A, Zawar V, Sciallis GF, et al. Pityriasis rosea, Gianotti-Crosti syndrome, asymmetric periflexural exanthem, papular-purpuric gloves and socks syndrome, eruptive pseudoangiomatosis, and eruptive hypomelanosis: Do their epidemiological data substantiate infectious etiologies? Infect Dis Rep 2016; 21;8:6418.

2. Drago F, Ciccarese G, Rebora A. Unilateral laterothoracic or asymmetric periflexural exanthem: Is time to change the name of the disease? Clin Exp Dermatol 2015; 40:570.

3. Niedermeier A, Pfützner W, Ruzicka T, et al. Superimposed lateralized exanthem of childhood: report of a case related to adenovirus infection. Clin Exp Dermatol 2014; 39:351-3.

4. Gragasin FS, Metelitsa Al. Unilateral laterothoracic exanthem. CMAJ 2012,21; 184:322.

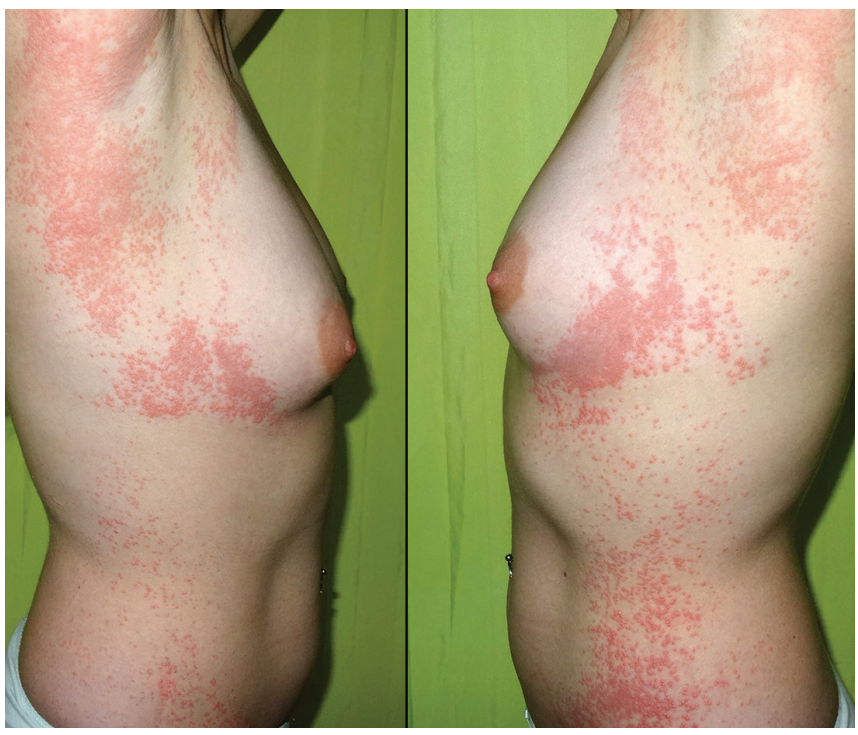

Figure 1: A 30-year-old woman with a papular rash on her lateral thorax bilaterally and abdomen following a diarrheal illness, diagnosed as superimposed lateralized exanthem.

\section{Competing interests: None declared.}

This article has been peer reviewed.

The authors have obtained patient consent.

Affiliation: Department of Dermatology, Reina Sofía University Hospital (Alcántara-Reifs, Salido-Vallejo) Córdoba, Spain

Correspondence to: Carmen María Alcántara-Reifs, ayla88_@hotmail.com

Clinical images are chosen because they are particularly intriguing, classic or dramatic. Submissions of clear, appropriately labelled high-resolution images must be accompanied by a figure caption. A brief explanation (300 words maximum) of the educational significance of the images with minimal references is required. The patient's written consent for publication must be obtained before submission. 